\title{
Non-puerperal Uterine Inversion: A Tertiary Category Hospital Case
}

\author{
Momo Romaric Joel Tetsiguia ${ }^{1}$, Medjom Doris ${ }^{1}$, Tsafack Marcellin ${ }^{2}$, Temkou Serge ${ }^{3}$ \\ ${ }^{1}$ Department of Obstetrics and Gynecology, Faculty of Medicine and Biomedical Sciences, University of Yaoundé I, Yaounde, Cameroon \\ ${ }^{2}$ Medicine Department, Higher Institute of Medical Technology, Yaounde, Cameroon \\ ${ }^{3}$ Obstetrician Gynecologist, Yaounde Central Hospital, Yaounde, Cameroon
}

Email address:

centrebfm@yahoo.fr (M. R. J. Tetsiguia)

\section{To cite this article:}

Momo Romaric Joel Tetsiguia, Medjom Doris, Tsafack Marcellin, Temkou Serge. Non-puerperal Uterine Inversion: A Tertiary Category Hospital Case. Journal of Gynecology and Obstetrics. Vol. 8, No. 1, 2019, pp. 1-3. doi: 10.11648/j.jgo.20200801.11

Received: October 6, 2019; Accepted: November 13, 2019; Published: January 6, 2020

\begin{abstract}
Introduction: Uterine inversion though rare is mainly seen in post-partum period. This paper documents a case of non-puerperal uterine inversion due to leiomyoma. Case presentation: We here in presents an unusual case of non-puerperal uterine inversion due to leiomyoma. A 62-year-old woman, G4P4004, with past history of a polymyomatous uterus presented polymorphous large mass bleeding at contact and coming out of the cervix. Management was surgical. The technique used consisted of an incision on the stricture but we could also proceed by a section of the exterior part and remove the rest by the abdominal approach. The post operatory period was normal. Conclusion: Uterine inversion is a rare pathology but can frequently be a consequence of gynaecological problem like intracavity leimyoma. The diagnosis is clinic and the treatment is surgical.
\end{abstract}

Keywords: Uterine Inversion, Leiomyoma, Management

\section{Background}

Uterine inversion is the intussusception of a part of the uterus through the cervix like a «glove finger». It is very rare, mainly seen in post-partum period. There are many causes of non-puerperal uterine inversion, which can be benign or malignancy. This is the case of non-puerperal uterine inversion due to leiomyoma.

\section{Case Presentation}

A 62 year-old woman, G4P4004 consults at the emergency ward for pelvic pain since 4 days, with a vaginal mass and mild to moderate bleeding. The patient has as past history a polymyomatous uterus with one of it intracavitary of size 9.2 $\mathrm{cm}$ and never treated. The physical examination showed a muco-cutaneous palor. Gynaecological exam revealed a polymorphous large mass, measuring $10 \times 8 \mathrm{~cm}$, bleeding at contact and coming out of the cervix. Uterine inversion stage 4 due to a polymyomatous uterus was diagnosed (Figure 1) and an emergency hysterectomy done; The first step of surgery was the section of the external part of the uterus, (Figure 2) and the second step the resection through laparotomy of the last part of the uterus (Figure 3). The post operatory period was normal and the patient went back home at the 7 th day.

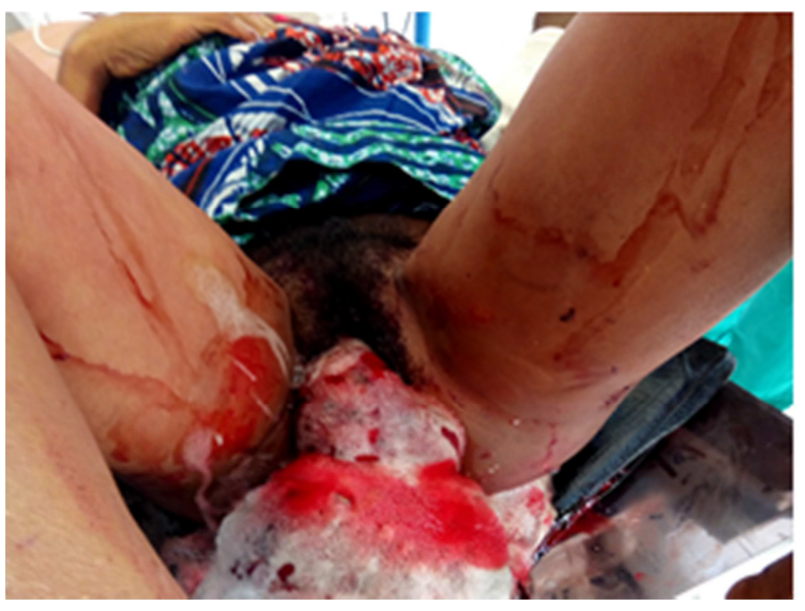




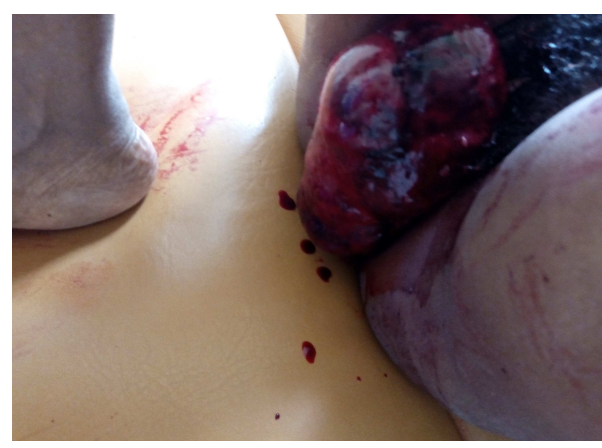

Figure 1. Uterine inversion stage 4.

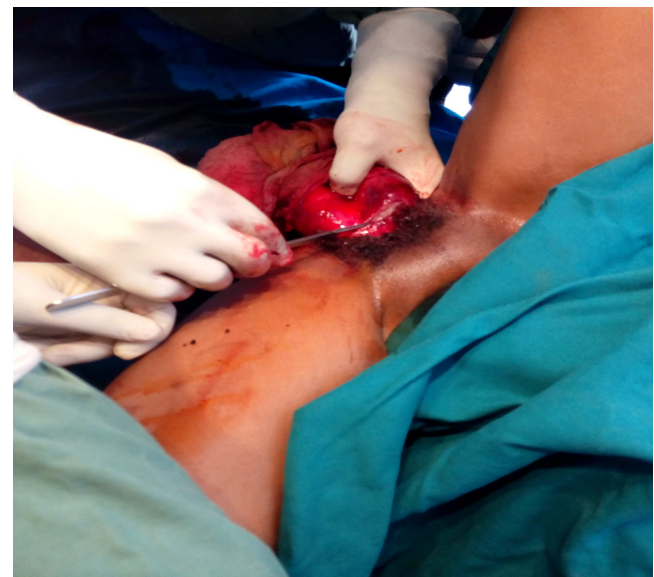

Figure 2. Treatment of our case by hysterectomy, on of the outer part of the uterus with clampage of uterine vessels.

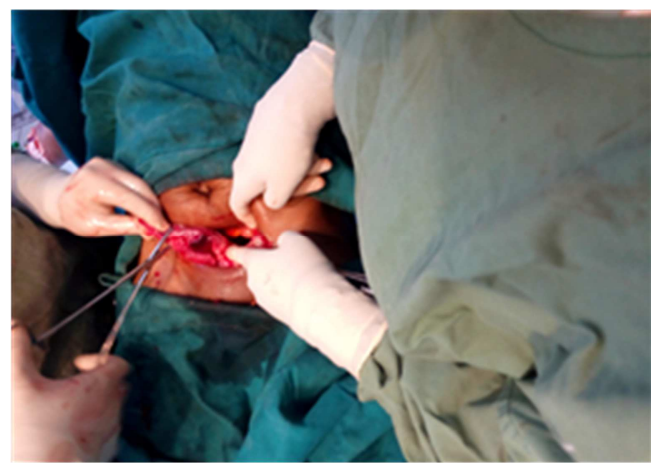

Figure 3. Treatment of our case, with removal of last part of the uterus.

\section{Discussion}

Uterine inversion is a rare gynaeco-obstetric disease. It can be puerperal or follow a gynecological problem. The frequency of puerperal uterine inversion is $1 / 30000$ and it represents $85 \%$ of all uterine inversion [1-2]. The frequency of non-puerperal uterine inversion is difficult to estimate. Gomez-lobo et al found that between 1887 to 2006 , only 150 cases of non-puerperal uterine inversion were documented [3].

The etiology can be found in more than $70 \%$ of cases. In few cases it can be idiopathic. The more frequent cause is sub-mucous myoma like in our patient which represents $71.3 \%$ of cases [4]. However, we can find malignant causes like leiomyosarcoma and endometrial cancer [3-5]. This disease is due to the presence of a mass with a pedicle in the uterine fundus, a thinning of the uterine wall, cervical dilatation and high abdominal pressu [6]. The combination of high pressure and uterine contraction put out the myoma and uterus wall through the cervix.

Uterine inversion can be acute or chronic, incomplete or total. We have 4 degrees depending on the portion of outer part of uterus [7]. The diagnosis is clinical, but not easily evoked sometimes. The patient can complaint of pelvic pain, intra-vaginal mass feeling, vaginal discharge or vaginal bleeding as seen in our patient [8]. During physical exam, there is an absence of the uterine fundus and the presence of this intravaginal mass [8].

The treatment of non-puerperal uterine inversion is surgery. The first principle of the surgery is to reduce the cervical and uterus lower segment spasm taking place after the passage of the uterus through the cervical canal [9]. the surgery can be radical or not. This depend of the age of patient, desire of conception, the etiology and the trophic status of uterus after reduction [9]. The surgery can be done by laparatomy, laparoscopy or vaginal but in some cases it is possible to combine all this techniques.

The abdominal way (approach) consists of two techniques; hauntain and huntington. The technique of huntington consists of clamping the round ligaments with Allis's pliers at the point of insertion with the uterus and exert a gentle traction force upright until correction of the inversion. Hauntain's own consists in doing a longitudinal incision till the ringed cervical stricture to reduce the constriction and facilitate by an upright traction the reversion of the uterus [10-11].

The vaginal way consists of the Twe and Kustner techniques. The technique of Twe, consists in the realization of an anterior hysterotomy after dissection of the cervical bladder, the inferior segment and then the restitution of the uterus. That of Kustner, consist in the realization of an incision of the cervix and the posterior part of the uterine corpus [10]. By the way, these techniques requiring first of all the re-integration of the uterus in the abdominal cavity may increase the risk of post-operative abdominal infection in the case of uterine inversion seen late. An hysterectomy was done in the case of our patient due to the age, parity and necrotic state of the uterus. In our case, the first steps of our surgery was the section of outer part of uterus, the next step was the ablation of the remain part of uterus through the abdominal approach. Theorically, this technique has permitted us to reduce the infectious risk but the main risk was related to the damage of ureters or bladder and bleeding. Even though, this bleeding risk is minimized due to the necrotic state of the uterus.

\section{Conclusion}

Uterine inversion is a rare pathology but can frequently be a consequence of gynaecological intracavity problem like leimyoma. The diagnosis is clinic and the treatment is surgical. This can be conservative or radical and its principle 
is based on the incision of the isthmo-cervical stricture. But in some case like in later seen with high risk of infection and necrosis, the first resection the outer part of uterus can be a subject of more research.

\section{Funding}

The authors did not receive any funding for this research.

\section{Availability of Data and Materials}

The authors declare that all data concerning this case report are provided within the manuscript.

\section{Authors' Contributions}

RM, JDS, EM, BS, PF managed the patient. RM drafted the initial manuscript which was modified by MNT and TM. All authors read and approved the final manuscript.

\section{Ethics Approval and Consent to Participate}

Our institution does not require ethics approval for case reports.

\section{Consent for Publication}

Written informed consent was obtained from the patient for publication of this case report and any accompanying images. A copy of the written consent is available for review by the Editor-in-chief of this journal.

\section{Competing Interests}

Authors declare no competing interests.

\section{Acknowledgements}

The authors are solely responsible for this manuscript preparation and decision to submit it for publication.

\section{References}

[1] Ueda, K, Okamoto, A, Yamada, K, et al. Non-puerperal inversion of the uterus associated with endometrial cancer: a case report. Int J Clin Oncol. 2006; 1: 153-5.

[2] Dayan SS, Schwalbe SS. The use of small dose intravenous nitroglycerin in a case of uterine inversion. Anesth Analg. 1996; 82: 1091-93.

[3] Gomez-Lobo, V and Burch, W. Nonpuerperal uterine inversion associated with an immature teratoma of the uterus in an adolescent. Obstet Gynecol. 2008; 112: 708-9.

[4] Katsumi T, Yoshihito I, Hajime $T$ et al. Uterine inversion caused by uterine sarcoma: a case report. Japanese Clin Oncol 2001; 31 (1): 39-42.

[5] Ueda K, Okamoto, A, Yamada K, et al. Non-puerperal inversion of the uterus associated with endometrial cancer: a case report. Int J Clin Oncol. 2006; 1: 153-5.

[6] Lupovitch A, England ER and Chen R. Non-puerperal uterine inversion in association with uterine sarcoma: case report in a 26-year-old and review of the literature. Gynecol Oncol. 2005; 97: $938-41$.

[7] Colette C, Gay C, Maillet R, Schaal JP (page consulté le 1511-2018). Inversion uterine, [En ligne]. http://www.syngof.fr/ syngof/fmc/inversion.html.2000.

[8] Nahid Eftekhari. Non-puerperal uterine inversion in a virgin woman. Iranian Journal of Reproductive Medicine. 2007; 5: 135-136.

[9] Leeya F, Kennedy O and Brett D. Non-Puerperal Uterine Inversion in a Young Woman: A Case Report, Brief Surgical Review, and Clinical Insights. Pinder et al. Clin Med Rev Case Rep 2016, 3: 122.

[10] Shamsudin F, Morton K. Novel correction technique of chronic puerperal inversion of the uterus. J Obstet Gynaecol. 2007; 27: 197-198.

[11] Shivanagappa M, Bhandiwad A, Mahesh M. A case of acute on chronic uterine inversion with fibroid polyp. J Clin Diagn Res. 2013; 7: 2587-2588. 